\title{
A New Methodology for the Temperature Testing of Thermostatic Chambers Used in the Food-Meat Industry
}

\author{
Dennis JANKOVICH, Krešimir OSMAN, Vili MILKOVIĆ
}

\begin{abstract}
This paper aims to develop a new testing methodology to evaluate the measurement uncertainty of temperature field of thermostatic chambers used in the foodmeat industry. The proposed methodology qualitatively evaluates the following parameters of a chamber's working space: mass of a product in a batch, thermal processing temperature, temperature in the geometric centre of product after shower cooling, duration of thermal processing, spatial temperature gradients and stability, heating and cooling dynamics between two temperature working points and temperature measurement uncertainty. As many different practical technical issues arose, by using the Response Surface Method, we analysed the impact of input test parameters to predict the unknown values of predefined output parameters based on known values of influential input parameters, and to actually rank each resulting impact of each input test parameter.
\end{abstract}

Keywords: measurement uncertainty; Response Surface Method; testing methodology; thermal processing; thermal processing temperature; thermostatic test chamber; working space

\section{INTRODUCTION}

Within different production facilities and testing laboratories of present-day food industry, the thermostatic test chambers are one of the most significant links in the process of quality control and assurance, and their performance should be subjected to detailed evaluation. This aims to allow its broad applicability to obtain all the relevant parameters with respect to the implementation, optimization and improvement of thermal processing of semi-durable meat products (TP) [1], and to control the value of all the principal thermodynamic influential parameters such as TP temperature $\left(T_{\mathrm{TP}}\right)$, duration of TP $\left(t_{\mathrm{TP}}\right)$, temperature in the geometric center of product after shower cooling $\left(T_{\mathrm{GC}}\right)$, and a product cooling time $[1,2]$. This research presents a new methodology for a qualitative testing and validation of thermostatic chambers used for TP. The main three thermodynamic parameters of the chamber working space are: the spatial temperature gradients, spatial temperature stability and heating and cooling dynamics between two temperature working points. The main motive for this research was to improve and update an existing obsolete thermostatic chamber testing methodology for TP. In most major food companies, they do not meet fundamental requirements [3] for the sustainable competitiveness of semi-durable meat products on the future common food market of the European Union Member States and North American Countries. For that reason, a new testing methodology needs to be supported by more recent improvements that will comply with different demands of present-day customers. The basic problem arises from a fact, that the present dynamics of cooling of semi-durable meat products after TP causes an undesirable impairment of almost all the mechanical properties $[4,5]$ of casings and skins and poor quality of distribution of edible matter in most semidurable meat products. In recent years, most European meat companies have replaced most of their old chambers of TP with completely new and modernized thermostatic chambers. The main reasons for such replacement are: obsolete geometric performance and control, and inability to continuously monitor the required increase in production. It arises from this that an existing old chamber control system fails to fully comply with the requirement of precisely maintaining the $T_{\mathrm{TP}}$ value [6], which is also main, defined working parameter. The newly installed thermostatic chamber for $\mathrm{TP}$ [7] is plant including smoking, boiling, sooting, frying, heating and baking of all the types of semi-durable meat products. As a result of demands for greater energy savings in chamber's operation, an entirely new process of TP has been developed and called "Delta Cooking" [8], which is characterized by very small losses in a product weight. As regards everyday engineering issues, the Response Surface Method (RSM) $[9,10]$ represents a highly efficient tool for finding and obtaining unknown outputs based on the known inputs, a possibility of predicting probable solutions based on the known outputs and classifications (ranks) of influence and effect of each parameter. During the experimental processing of all information obtained for two-factor and three-factor experiments, we used the Design Expert software package, version DOE 7.1.6 (Design of Experiments) [11], to plan and analyze our experiments. The problem was reduced to determining the influential input parameters on the output parameter $t_{\mathrm{TP}}$. The thermodynamic process of conductive heat transfer [12] is assumed as a physical model of forced convection, i.e. the flowing of dry saturated steam on the transversal pipe beam (vertically hanging batch of selected product "Krainer Sausage"). The assumed parameters have a significant impact on the heat transfer coefficient [13]. This impact has an effect of saturated steam streaming to the thermal processing sausage batch (defined model of the heat transfer direction is: saturated steam $\rightarrow$ exterior side of sausage $\rightarrow$ geometric center of sausage). Mentioned assumed parameters are defined as input-influential parameters that have a direct impact on output-preset parameter, which is $t_{\mathrm{TP}}$. The selected influential parameters: mass of a product in a batch $(m), T_{\mathrm{TP}}$ and $T_{\mathrm{GC}}$ are input parameters and only $t_{\mathrm{TP}}$ is the output parameter.

\section{DEFINITION OF EXPERIMENT}

These experiments represent the satisfactory dependence of two mathematical functions (models) in the used software package. The two factor and three-factor 
experiments were conducted according to the literature $[14,15]$ and Fig. 1 presents both of them.

The first case was an experiment defined by two assumed influential input parameters $m$ and $T_{\mathrm{TP}}$, while the assumed output parameter was $t_{\mathrm{TP}}$. The second experiment was defined by three assumed influential input parameters of which the first two are identical as in the first case, while the third one was defined as $T_{\mathrm{GC}}$, and the assumed output parameter was identical as in the first case, $t_{\mathrm{TP}}$. In the next report, we will give an analysis of DOE data for two-factor experiment.

\subsection{Report of the Two-Factor Experiment}

The response is $t_{\mathrm{TP}}$ parameter and an analysis of variance (ANOVA) for the RSM is a quadratic model. The ANOVA table is a partial sum of squares. For the twofactor experiment, the quadratic model [11] yielded as the only valid satisfactory input/output parameter dependence model. The experiment was carried out using "Design Expert" software, version 7.1.6.

The Model F-value of 53,71 implies that this model is significant! There is only a $0,01 \%$ chance that the "Model
F-value" this large could occur due to noise. The values of "Prob $>\mathrm{F}$ " less than 0,0500 indicate that model terms are significant. In this case $A, B, A B, A^{2}$ and $B^{2}$ are significant model terms! The values greater than 0,1000 indicate that model terms are not significant! If there are many insignificant model terms (not counting those required to support a hierarchy), a model reduction may improve this model. The "Lack of Fit F-value" of 0,43 implies that the "Lack of Fit" is not significant relative to the pure error. There is a $82,06 \%$ chance that the "Lack of Fit F-value" this large could occur due to noise. Non-significant lack of a fit is good (we want the model to fit). The "Pred RSquared" of 0,8755 is in reasonable agreement with the "Adj R-Squared" of 0,9564. The "Adeq Precision" measures the signal to noise ratio used to navigate the design space. The final equation in terms of all the actual factors is the next:

$$
\begin{aligned}
& t_{\mathrm{TP}}=1,31141 \times 10^{5}= \\
& =8,87151 \cdot m-3357,83705 \cdot T_{\mathrm{TP}}-0,11759 \cdot m \cdot T_{\mathrm{TP}}+ \\
& +2,48256 \times 10^{-4} \cdot m^{2}+21,51883 \cdot T_{\mathrm{TP}}^{2}
\end{aligned}
$$

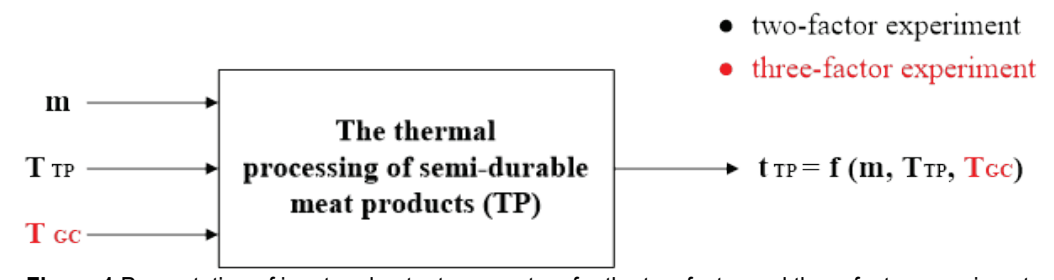

Figure 1 Presentation of input and output parameters for the two-factor and three-factor experiments

Table 1 The results of the two-factor experiment

\begin{tabular}{|c|c|c|c|c|c|c|}
\hline Source & Sum of squares & df & Mean square & F-value & P-value, Prob $>$ F & $<0,0001$ \\
\hline Model & $1,397 \times 10^{5}$ & 5 & $27.948 .8153,71$ & & 30,53 & significant \\
\hline$A-m$ & $15.889,89$ & 1 & $15.889,89$ & $4.395,03$ & 8,45 & 0009 \\
\hline$B-T_{\mathrm{TP}}$ & $4.395,03$ & 1 & 1 & $40.543,26$ & 77,91 & $<0,0001$ \\
\hline$A B$ & $40.543,26$ & $54.149,56$ & 1 & $54.149,56$ & 104,06 & $<0,0001$ \\
\hline$A^{2}$ & $33.121,88$ & 1 & $33.121,88$ & 63,65 & $<0,0001$ \\
\hline$B^{2}$ & $3.642,74$ & 7 & 520,39 & & & \\
\hline Residual & $2.630,24$ & 6 & 438,37 & 0,43 & & \\
\hline Lack of Fit & $1.012,50$ & 1 & $1.012,50$ & & & \\
\hline Pure Error & $1,434 \times 10^{5}$ & 12 & & & \\
\hline Cor Total & & & & \\
\hline
\end{tabular}

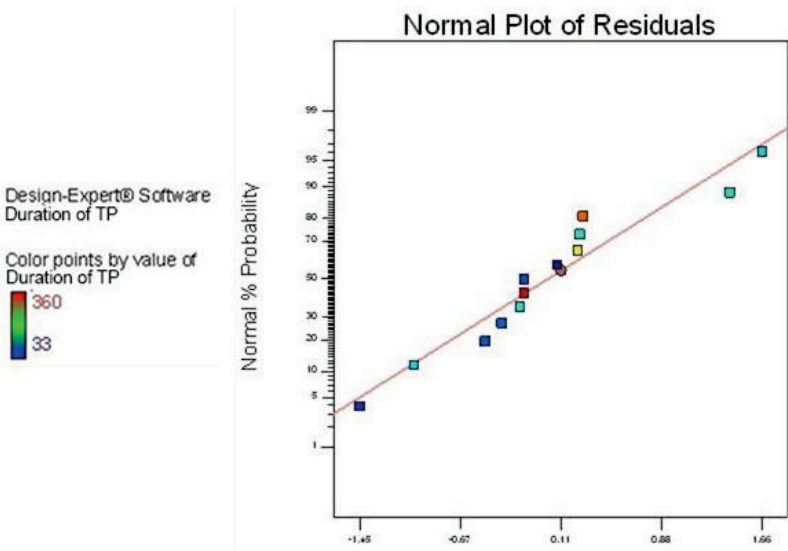

Internally Studentized Residuals Figure 2 Internally studentized residuals

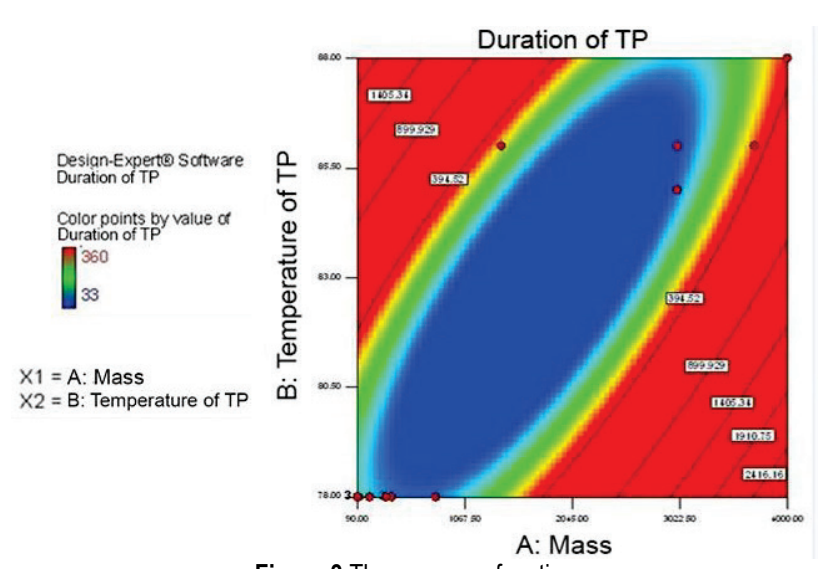

Figure 3 The response function

\subsection{Report of the Three-Factor Experiment}

The response is $t_{\mathrm{TP}}$ parameter and an ANOVA for the RSM is a cubic model. The ANOVA table is a partial sum 
of squares. For three-factor experiment, the cubic model [11] yielded as the only valid satisfactory input/output parameter dependence model. As in the previous case "Design Expert" software, version 7.1.6. was also carried out.

The Model F-value of 7,27 implies that this model is significant! There is only a 3,42\% chance that the "Model F-value" this large could occur due to noise. The values of

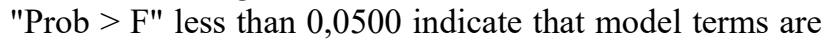
significant. In this case $C, A B, A C, A^{2}, A B C, A^{2} C, A C^{2}$ and $C^{3}$ are significant model terms. The values greater than 0,1000 indicate that model terms are not significant! If there are many insignificant model terms (not counting those required to support a hierarchy), a model reduction may improve this model. The Case(s) with leverage of 1,0000: the "Pred R-Squared" and PRESS statistic not defined the "Adeq Precision" measures the signal to noise ratio. A ratio greater than 4 is desirable! Our ratio of 7,788 indicates an adequate signal. This model can be used to navigate the design space. The final equation in terms of all the coded factors is:

$$
\begin{aligned}
& t_{\mathrm{TP}}=-71279,35 \cdot C+44467,57 \cdot A \cdot B-72584,75 \cdot A \cdot C- \\
& -12195,07 \cdot A^{2}+52675,61 \cdot A \cdot B \cdot C-14542,38 \cdot A^{2} \cdot C- \\
& -73767,06 \cdot A \cdot C^{2}+38358,38 \cdot C^{3}
\end{aligned}
$$

Table 2 The results of the three-factor experiment

\begin{tabular}{|c|c|c|c|c|c|c|}
\hline \multicolumn{9}{|c|}{ Table 2 The results of the three-factor experiment } & P-value, Prob> F \\
\hline Source & Sum of squares & df & Mean square & F-value & 0,0342 \\
\hline Model & $2,415 \times 10^{5}$ & 15 & $16.097,20$ & 7,27 & 0,2823 \\
\hline$A-m$ & $3.413,29$ & 1 & $3.413,29$ & 1,54 & 0,0560 \\
\hline$B-T_{\mathrm{TP}}$ & $15.739,34$ & 1 & $15.739,34$ & 7,11 & 0,0043 \\
\hline$C-T_{\mathrm{GC}}$ & $75.571,13$ & 1 & $75.571,13$ & 34,12 & 0,0322 \\
\hline$A B$ & $23.012,72$ & 1 & $23.012,72$ & 10,39 & 0,0041 \\
\hline$A C$ & $77.264,85$ & 1 & $77.264,85$ & 34,89 & 0,0072 \\
\hline$A^{2}$ & $56.395,54$ & 1 & $56.395,54$ & 25,47 & 0,0321 \\
\hline$A B C$ & $23.056,40$ & 1 & $23.056,40$ & 10,41 & 0,0079 \\
\hline$A^{2} C$ & $53.696,52$ & 1 & $53.696,52$ & 24,25 & \\
\hline$A C^{2}$ & $56.794,71$ & 1 & $56.794,71$ & 25,65 & \\
\hline$C^{3}$ & $20.027,93$ & 1 & $20.027,93$ & 9,04 & \\
\hline Residual & $8.858,50$ & 4 & $2.214,63$ & & 0,0072 \\
\hline Lack of Fit & $8.858,50$ & 3 & $2.952,83$ & & \\
\hline Pure Error & 0,00 & 1 & 0,0397 & \\
\hline Cor Total & $2,503-10^{5}$ & 19 & & & \\
\hline
\end{tabular}

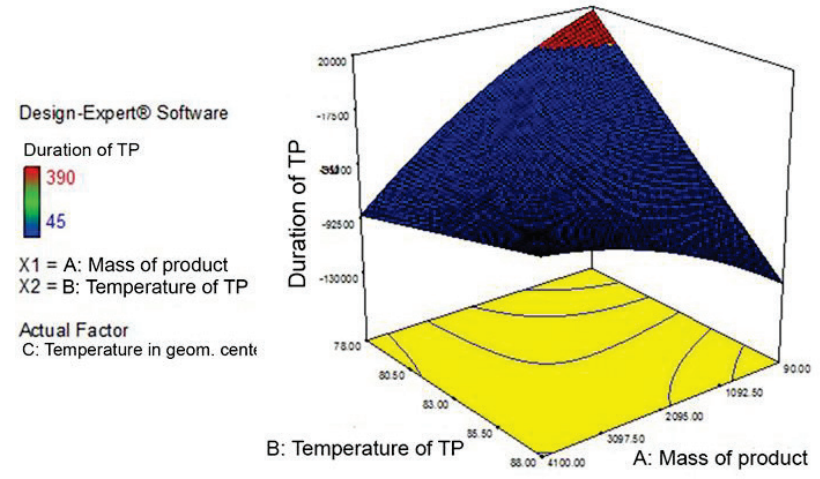

Figure 4 Internally studentized residuals

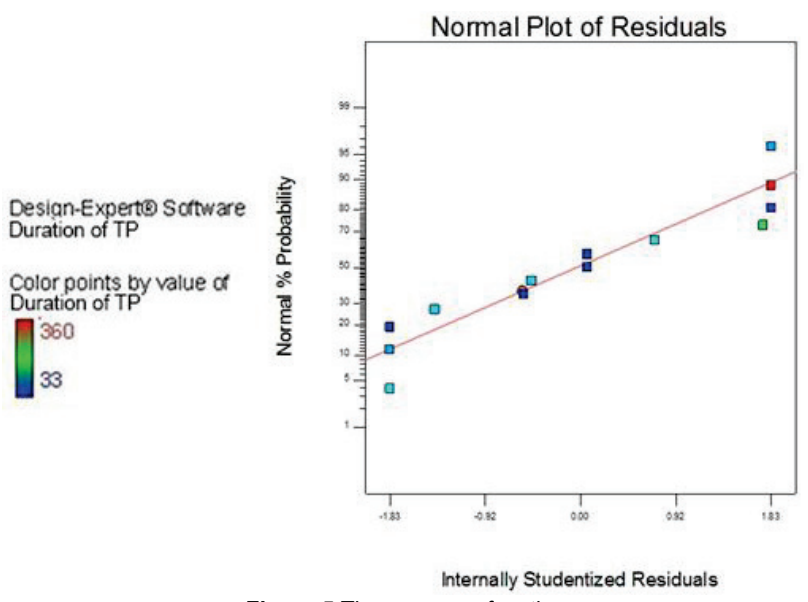

Figure $\mathbf{5}$ The response function

The RSM provides and evaluates an optimized procedure of selecting all the influential parameters, which can reflect the real preference in the next proposal testing methodology of any thermostatic chamber's working space used in the food industry.

\section{TESTING METHODOLOGY}

The observed thermostatic test chamber was tested in an area located away from direct impact of daylight, but still under sufficient influence of ventilated exterior air. The used test chamber ensures a three-dimensional closed working space with high air temperature stability. Consequently, this type of test chamber has a working space with fully controlled air temperature. For the purpose of evaluating quality of the working space, the proposed and applied testing methodology defines 3 main characteristics of the most influential parameter, i.e. air temperature in TP: spatial temperature gradients, spatial stability of $T_{\mathrm{TP}}$ and heating/cooling dynamics between 2 temperature points within the working space. The targeted development of such new testing methodology to evaluate the quality and to optimize the process of $\mathrm{TP}$ requires effective control of predefined main influential parameters such as: $T_{\mathrm{TP}}, t_{\mathrm{TP}}$, heating/cooling speed, and spatial temperature stability within working space. A thermostatic test chamber is defined as a chamber with forced convection. Because of the great importance of obtaining an integral measurement results, this testing used platinumresistance thermometers as the measuring temperature sensors were placed inside the working space. According to the literature [16], the measuring sensors are placed in the working space by determining experiential distance of approx. 1/10 of width (height, depth) between a border 
zone and each test chamber's wall. The measuring sensors are placed in 2 or 3 equal spatial level-planes, which are parallel to the rear wall of chamber. The number of measurement points is defined for each level-plane, and the ranges between up to 9 for the large volume chambers and 5 for the small volume chambers, and the circular cross section chambers (see Fig. 1, [16], page 2). In this case, we tested ASL 3641 type of thermostatic chamber (manufacturer: "Maurer $\mathrm{AG}^{\text {") }}$ having interior volume of $11,47 \mathrm{~m}^{3}$, which is classified as a large chamber [7]. The temperature sensors were placed within the working space of thermostatic test chamber as presented in Fig. 6.

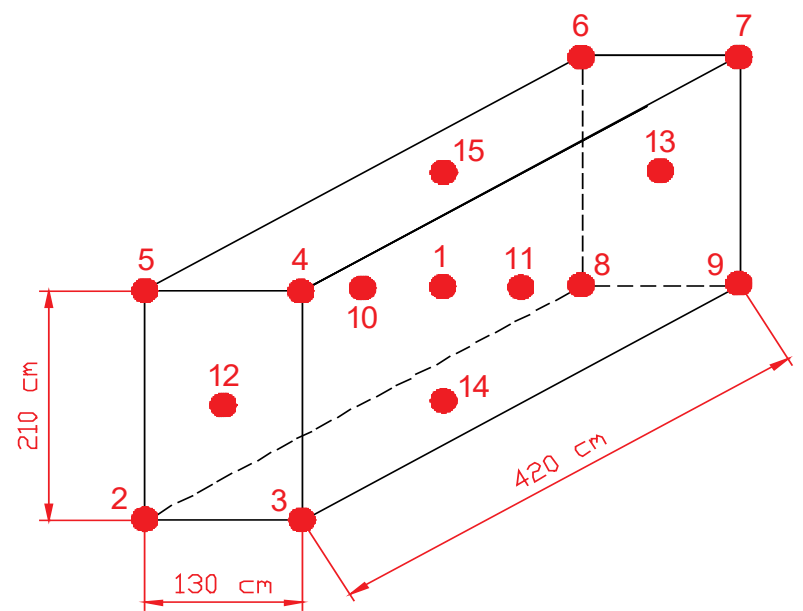

Figure 6 The spatial placement of 15 temperature sensors in thermostatic test chamber

To adhere to such test chamber's classification and to provide greater accuracy of the measurement results, we set a total of 15 measuring sensors within the working space (see Fig. 3, [17], Section 7.1.1.2, page 13). It is necessary to define at least 3 set points (SP) at 5\%, 50\% and $95 \%$ temperature load within the working space. The procedure of the air temperature measuring starts by setting the selected set temperature value $T_{S P}$ at SP by using the steam heater regulator, after which the measured temperature values are recorded and stored in the regular time intervals of $1 \mathrm{~s}$, starting from the value of $T_{\mathrm{RP}}$ at reference point (RP) and proceeding to the set temperature value $T_{\mathrm{SP}}$ at SP in TP process. These results are in a set of the measured temperatures $T_{i, j}$ at the measurement points $i$ $=1,2, \ldots, N$ in a time interval for each measurement point. According to the literature [16] by using Eqs. (1)-(15), it is possible to define the following 2 parameters: An average share of temperature increase $\Delta T_{\mathrm{RP}} / \Delta \tau$ at RP which can be defined by using Eq. (1), and a spatial stability of $T_{\mathrm{TP}}$. The test measurements begin after the temperature stability is achieved at SP, and all the temperature values are stored within a total time interval set for the process of TP of each selected semi-durable meat product, which ultimately results in the set of measured temperatures $T_{i, j}$. As the spatial temperature gradients and temperature instabilities have different sources of their origin, we prefer a mathematical model of temperature instability based on the separate time bases. It arises from that the time-averaged temperatures on such measurement points $i$ are defined as a temperature arithmetic mean $T_{i, d}$ by using Eq. (2). The maximum temperature instabilities $\delta T_{d}$ at point $\left(i, \delta T_{i, d}\right)$ are calculated by using Eq. (3). The maximum spatial deviation of time-averaged temperatures is separately calculated for the positive $\Delta T_{\mathrm{RP}+, d}$ and negative $\Delta T_{\mathrm{RP}-, d}$ deviations by using Eqs. (5)-(6). The maximum spatial temperature deviation $\Delta T_{\mathrm{RP}, d}$ in relation to the test chamber's RP is defined by using Eq. (7) and the maximum spatial temperature gradient through the working space $\Delta T_{\mathrm{C}, d}$ is calculated according to Eq. (8). For the temperatures $T_{i, d}(i=1,2, \ldots, N)$, the temperature drift may be estimated by using Eq. (3). The deviations of a timeaveraged temperature $T_{\mathrm{RP}, d}$ at $\mathrm{RP}$ in relation to the temperature set at current SP $T_{\mathrm{SP}}$ within the test chamber, $D T_{\mathrm{SP}}$ is calculated by using Eq. (15). An ambient temperature within the working volume (see [17], Section 8.4 , page 15) results in the readouts of temperature values at all the measuring sensors, which are then stored as a maximum every minute. At least 30 recordings per measuring sensor are taken and a duration of temperature measurements is at least 30 minutes. The first step is determining the mean temperature value of each measuring sensor $T_{m, j}$. The second step is to determine an air temperature.

The measurement uncertainty at exit of the test chamber's measurement system is determined using an appropriate calibration system of the observed test chamber [7]. The temperature sensors are Pt-100 contact resistance sensors. A time interval of $10 \mathrm{~s}$ to $40 \mathrm{~s}$ should account for $50 \%$ of each measuring sensor's response time, while an entire system's response time must be less than 40 $\mathrm{s}$ (see [18], Section 4.2, page 15). To confirm a monitoring, the measurement data must be recorded at least once a minute. The temperature change share is determined as follows (see Fig. 8, [17], Section 9.5, page 21).

\section{DESCRIPTION OF THE NEW TEST AND MEASUREMENT LINE}

The purpose of a new test and measurement line is to monitor and control the even distribution of $T_{\mathrm{TP}}$ within the working space in a standard operating process of TP. This line consists of a multichannel data system, including as its main components: PC, measuring and central monitoring software package, network multichannel multiplexer, input/output module (card), temperature measuring sensors and connecting/signal cables. The used "LabVIEW" software package enables an effective monitoring of industrial production and facilitates the processing of data gathered. The data is collected by a sampling using of multichannel multiplexer, and it is transferred using an information network, scaled and used to develop a visual interface and database. The scaled data is stored in a database and is then simultaneously processed and numerically and graphically displayed. The user creates a database and the data stored therein can be used for further processing and gathering of information in the numerical and graphic formats. In this case, we use 2 input/output modules with a total of 16 channels (measuring sensors). The module is designed to receive up to 8 measuring sensors (in this case 2 input modules receive a total of 16 measuring sensors). The period of refreshing (updating) data from all the channels (a total of 16 channels) is $1,08 \mathrm{~s}$ and associated error is $0,016^{\circ} \mathrm{C}$. This module uses its own processor to linearize and scale the input signals within a predefined temperature range. The measuring sensors 
triple core connection eliminates any measuring errors resulting from a cable length.

Table 3 The results of final evaluation of thermostatic test chamber

\begin{tabular}{|c|c|c|c|c|c|}
\hline \multirow{2}{*}{ The temperature set points } & \multicolumn{5}{|c|}{ Temperature } \\
\hline & Parameter & Ref. & Eq. & Value & $u_{m j}$ \\
\hline The average share of temperature increase at RP. & $\Delta T_{\mathrm{RP}} / \Delta \tau$ & {$[16]$} & (1) & $15,25^{\circ} \mathrm{C} / \mathrm{h}$ & --- \\
\hline The maximum spatial temperature deviation in relation to the test chamber's RP. & $\Delta T_{\mathrm{RP}, d}$ & {$[16]$} & (7) & $0,34^{\circ} \mathrm{C}$ & $0,3^{\circ} \mathrm{C}$ \\
\hline The maximum spatial temperature gradient through working space. & $\Delta T_{\mathrm{C}, d}$ & [16] & (8) & $0,54{ }^{\circ} \mathrm{C}$ & $0,3^{\circ} \mathrm{C}$ \\
\hline $\begin{array}{l}\text { The maximum temperature instabilities at point }\left(i, \delta T_{i, d}\right) \text { that reflects a quality of the test chamber's } \\
\text { temperature control circle. }\end{array}$ & $\delta T_{d}$ & {$[16]$} & (3) & $0,13{ }^{\circ} \mathrm{C}$ & $0,0^{\circ} \mathrm{C}$ \\
\hline $\begin{array}{l}\text { The deviation of time-averaged temperature at RP in relation to the temperature set at the current SP } \\
\text { within the test chamber. }\end{array}$ & $D T_{\mathrm{SP}}$ & [16] & (15) & $0,04{ }^{\circ} \mathrm{C}$ & $0,2^{\circ} \mathrm{C}$ \\
\hline
\end{tabular}

THE THERMAL PROCESSING OF SEMI-DURABLE MEAT PRODUCTS (TP)

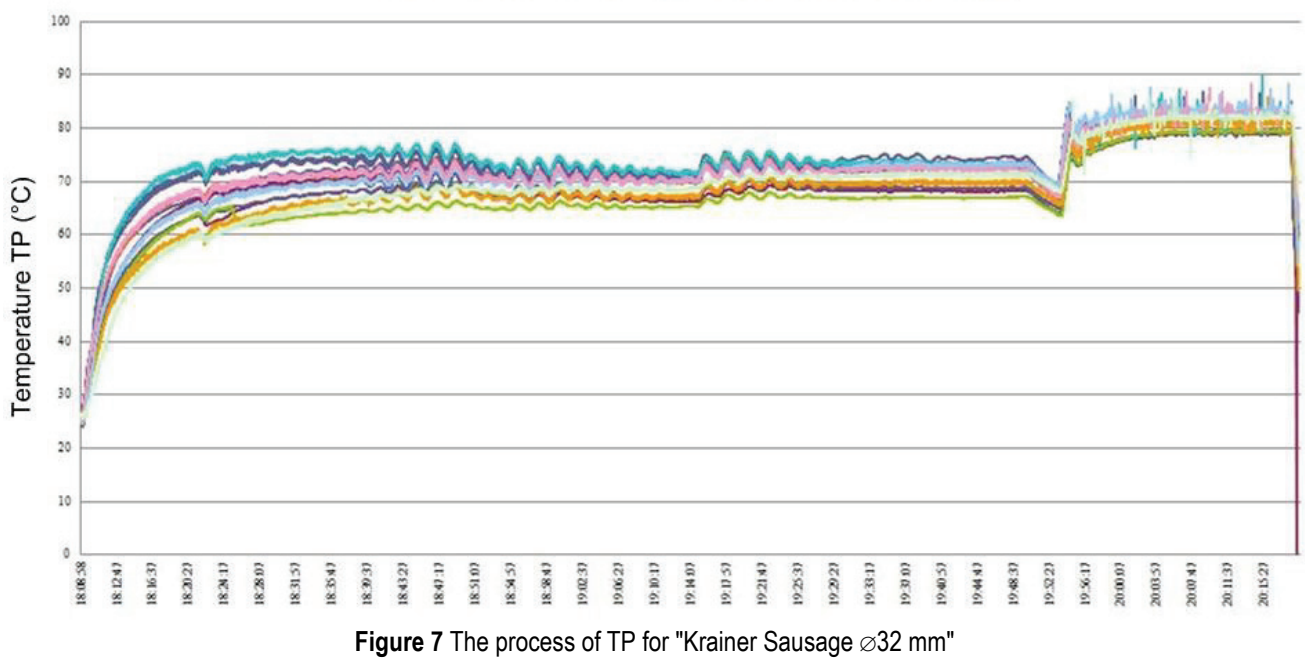

\section{MEASUREMENT UNCERTAINTY}

The measurement uncertainty $[19,20]$ is a numerical indicator of a measurement result's quality. It is expressed by a standard deviation (standard measurement uncertainty, $u$ ) or a standard deviation multiple (expanded measurement uncertainty, $U$ ). According to the literature [20] of our evaluation method, the uncertainty components are divided into 2 groups: the first group comprises components $u_{A}$ determined by using the statistical methods, while the other group comprises components $u_{B}$ that are estimated by other ways (most commonly by using equivalent standard deviation) [21]. What is critical for this case is a measurement uncertainty of platinum resistance thermometer that consists of the following measurement uncertainty components: uncertainty of observed thermometer as specified in the calibration certificate, uncertainty of the resistance bridge as specified in the calibration certificate, uncertainty of the thermometer drift, uncertainty of a gradient (bath, furnace) and uncertainty of the gauging instrument (calibrator) resolution. The measurement uncertainty is considered as a type A [22-24] in $i$ measurement points at $95 \%$ reliability. By stabilizing the temperature at all the 15 measuring points within the working space, we achieved the defined constant value of allowed deviation of $\pm 0,5{ }^{\circ} \mathrm{C}$ between its actual and set values. These changes are evaluated by using the operator's graphic readouts and their evaluation is a source of measurement uncertainty $[25,26]$ for the beginning of measurement. There are no types of interference other than normal; the initial interference situation is established as soon as we obtain dispersion of the temperature parameter mean value, which does not substantially change over time. The measurement record is divided into several equal time intervals during each measurement, and temperature has an infinite number of values (see [17], Annex C, page 38). It is predefined by using the mean temperature value and variance parameters. We predefined the number of repeated measurements $k=30$ performed during each time interval $i$. The mean temperature value $x_{i, d}$ is defined by an expression used to calculate "actual mean value" of temperature within the time interval $i$. The measurement uncertainty test includes a verification of 4 selected hypotheses (hypotheses A, B, C and D) with a reliability limit of $95 \%$ for each observed time interval (see [17], Annex C, page 38-40). The measurement uncertainty estimation is based on the mean temperature values for each sensor and includes 3 basic components that should never be ignored (see [17], Section D.1.2.1, page 40-41). The first component is a repeatability which is evaluated by using an experimental standard deviation $s_{j}$ and a notstandard error of mean value. The second component is defined as $s_{j}$ which shows any changes in the observed measured parameter by using $j$ temperature measuring sensors. The third component is defined as a compound measurement uncertainty of chamber measurement system $u_{c j}$, which consists of temperature measuring sensors, converter, screen and other ancillary parts. The final value of compound measurement uncertainty $u_{m j}$ is estimated by using an expression including an experimental standard deviation component $s_{j}$ and a compound measurement uncertainty component of chamber measurement system $u_{c j}$, while an expanded measurement uncertainty $U_{m j}$ is 
estimated by using an expression including an expansion factor $k_{f}=2$ (see [17], Section D.1.2.1, page 41).

\section{DISCUSSION OF RESULTS}

The final evaluation of thermostatic test chamber [27] is obtained from the measurement uncertainty of temperature field established within the working space during the process of TP for the meat product "Krainer Sausage $\varnothing 32 \mathrm{~mm} "$. The results of final evaluation are presented in Tab. 3. The mean temperature value at RP in an initial time interval of $1 \mathrm{~s}$ for all the 15 installed temperature sensors was $26,03{ }^{\circ} \mathrm{C}$, while $T_{\mathrm{TP}}$ was predefined as $T_{\mathrm{TP}}=T_{\mathrm{SP}}=78^{\circ} \mathrm{C}$. The value increase at $T_{\mathrm{TP}}$ in relation to the initial value of $26,03{ }^{\circ} \mathrm{C}$ up to the specified temperature value $T_{\mathrm{SP}}$ is presented in Fig. 7. The measurement uncertainty is considered to be a type A for the total of 15 temperature sensors with $95 \%$ reliability. The spatial temperature stability at each measurement point within the working space resulted in a defined constant value of $T_{\mathrm{TP}}$ allowed deviation of approx. $\pm 0,5^{\circ} \mathrm{C}$, as between its actual and defined values [28]. The methodology proposed took into consideration the defined thermodynamic parameters to evaluate the measurement uncertainty of resulting temperature field [29]: $\Delta T_{\mathrm{RP}} / \Delta \tau$, $\Delta T_{\mathrm{RP}, d}, \Delta T_{\mathrm{C}, d}, \delta T_{d}$ and $D T_{\mathrm{SP}}$. The results of final evaluation present an air heating/cooling dynamics within the working space between 2 temperature working points, the individual and aggregate influences of all the influential parameters, and an evaluation of associated measurement uncertainty.

\section{CONCLUSION AND DIRECTIONS OF FUTURE RESEARCH}

The new testing methodology proposed and used is defined as a model of the test/measurement/information system for collecting data on a particular semi-durable meat product. A review of theoretical field was used to learn about a series of assumed and actual influential characteristics that inevitably affect the observed process of TP within the thermostatic test chamber working space. Such influential characteristics define the basic requirements that must be considered when defining the test/measurement/information infrastructure for the presented model. This paper describes the RSM that provided a relevant information about the number and ranks of all the relevant influential parameters with respect to the observed process of TP and the final product itself. We will underscore as an important step in this method, a selection of input influential parameters and the intended output parameter in defining and conducting the two-factor and three-factor experiments. The authors see further research in an integration of the presented testing methodology and a new one with all the phases in lifecycle of both, present and future, completely new semi-durable meat products. The described model for collecting relevant data about a particular semi-durable meat product should be extended to initial phase of observed process of TP, where above mentioned issues arise in the form of unwanted volume deformation and poor distribution quality (porosity) of product's edible matter, which was in particular reported for observed product "Krainer Sausage $\varnothing 32 \mathrm{~mm} "$. The issue of integrating proposed testing methodology with other computing tools that technologists currently use on a daily basis in a meat industry remains open. What is not considered in this paper, but may be predicted with a great certainty is a need to include all the measurement data associated with a product's geometry. The methodology for evaluating an impact of all the influential parameters on an uncertainty of temperature field within the working space is detailed in this paper and opens to further discussion. Also, as a future research, the authors propose an investigation of usage of similar statistical methods (such as a statistical method of Multiple Regression Analysis) and give an overview of comparison with the results obtained with the RSM applied in this paper.

\section{REFERENCES}

[1] Čaklovica, K., Smajlović, M., Čaklovica F., Alagić D., \& Članjak E. (2011). The effect of thermal treatment bycooking and storage on viability of Listeria monocytogenes in frankfurters. The First Croatian Meat Journal MESO, 13(3), 179-185.

[2] Pravilnik o mesnim proizvodima "Narodne novine" br. 131/12 (Rules on meat products "Official Gazette" No. 131/12), Zagreb, Croatia, 2012, http://www.propisi.hr

[3] Tovunac, I., Galić, K., Prpić, T., \& Jurić, S. (2011). Effect of packaging conditions on the shelf-life of chicken frankfurters with and without lactate addition. Food Science and Technology Journal, 17(2), 167-175. https://doi.org/10.1177/1082013210381952

[4] Bakker, W. A. M., Houben, J. H., Koolmees, P. A., Bindrich, U., \& Sprehe, L. (1999). Effect of initial mild curing, with additives, of hog and sheep sausage casings on their microbial quality and mechanical properties after storage at difference temperatures. Meat Science Journal, 51(2), 163174. https://doi.org/10.1016/S0309-1740(98)00118-1

[5] Gorbatov, A. V. \& Gorbatov, V. M. (1974). Advances in sausage meat rheology. Journal of Texture Studies, 4(4), 406-437. (Article first published online: January $30^{\text {th }}$ 2007)

[6] Vujadinović, D. \& Marjanović-Balaban, Z. (2012). Influence of temperature and heat treatment regime on chemical properties of pork meat. Quality of Life Journal, 3(3-4), 4954. https://doi.org/10.7251/QOL1203049V

[7] Technical documentation, Chamber for thermal processing of meat products (type ASL 3641, manufacturer "Maurer AG", Germany), 2003.

[8] Lagares, J. (2006). Cooking process for whole-muscle products. Meat Science Journal, 16(4), 28-30.

[9] Breyfogle III, F. W. (1993). Statistical methods for testing development and manufacturing. IBM-Corporation, Austin, Texas.

[10] Bucher, C. G. (1990). A fast and efficient response surface approach for structural reliability problem. Structural Safety Journal, 7(1), 57-66. https://doi.org/10.1016/0167-4730(90)90012-E

[11] Manual/Tutorials, Design Expert 7.1.6, http://legacy.statease.com/de71_man.html

[12] Kothandaraman, C. P. (2006). Fundamentals of heat and mass transfer. New Age International (P) Ltd. Publishers, New Delhi.

[13] Bockh, P. \& Wetzel, T. (2012). Heat Transfer. SpringerVerlag Berlin Heidelberg, Berlin. https://doi.org/10.1007/978-3-642-19183-1

[14] Mendenhall, D. (1994). Design and analysis of experiments. John Wiley and Sons Inc., New York.

[15] Montgomery, D. C., Mayers, R. (1995). Response surface metodology. John Wiley and Sons Inc., New York. 
[16] Zvizdić, D., Šerfezi, D., \& Grgec-Bermanec, L. (2002). Assessment of temperature field in environmental and thermostatic test chambers. Proceedings of the $8^{\text {th }}$ Int. Symposium on Temperature and Thermal Measurements in Industry and Science Tempmeko 2001. / Berlin 2001. (edited by Fellmuth B., Seidel, J., Scholz, G. VDE VERLAG Gmbh, 693-698).

[17] French Norm NF X 15-140, AFNOR, Saint-Denis, 2002, http://www.euramet.org, http://www.afnor.fr

[18] International Standard IEC 60068-3-5, Edition 1.0, IEC, Geneva, 2001, http://www.iec.ch

[19] EURACHEM, Quantifying uncertainty in analytical measurement, 2007, $\mathrm{http} / / / \mathrm{www}$.measurementuncertainty.org

[20] JCGM, JCGM 100:2008, Evaluation of measurement data Gide to the expression of uncertainty in measurement (GUM 1995 with minor corrections), Working group 1 of the joint committee for guides in metrology (JCGM/WG1), 2008, http://www.iso.org

[21] Guideline DKD-R 5-1, Calibration of resistance thermometers, (English translation 2009), Edition 10, Germany, 2003, http://www.dkd.eu

[22] Choi, J., Hwang, E., So, H. Y., \& Kim, B. (2003). An uncertainty evaluation for multiple measurements by GUM. Accreditation and Quality Assurance Journal, 8(1), 13-15. https://doi.org/10.1007/s00769-002-0520-9

[23] Choi, J., Kim, D. H., Hwang, E., \& So, H. Y. (2003). An uncertainty evaluation for multiple measurements by GUM. Accreditation and Quality Assurance Journal, 8(1), 205-207. https://doi.org/10.1007/s00769-003-0614-z

[24] Ellison, S. L. R. \& Barwick, V. J. (1998). Using validation data for ISO measurement uncertainty estimation. Part 1. Principles of an approach using cause and effect analysis. Analyst Journal, 123(6), 1387-1392. https://doi.org/10.1039/A706946D

[25] Dieck, R. H. (2007). Measurement uncertainty: Methods and applications. $4^{\text {th }}$ ed. Research Triangle Park, NC: The Instruments, Systems, and Automation Society (ISA).

[26] Taylor, J. R. (1997). An introduction to error analysis: The study of uncertainties in physical measurements. $2^{\text {nd }}$ ed. Sausalito: University Science Books.

[27] Populaire, S. \& Gimenez, E. C. (2006). A simplified approach to the estimation of analytical measurement uncertainty. Accreditation and Quality Assurance Journal, 10(9), 485-493. https://doi.org/10.1007/s00769-005-0036-1

[28] Kirkup, L. \& Frenkel, R. B. (2006). An introduction to uncertainty in measurement using the GUM. University Press, Cambridge. https://doi.org/10.1017/CBO9780511755538

[29] Peters, R. J. B., Elbers, I. J. W., Klijnstra, M. D., \& Stolker, A. A. M. (2011). Practical estimation of the uncertainty of analytical measurement standards. Accreditation and Quality Assurance Journal, 16(11), 567-574. https://doi.org/10.1007/s00769-011-0829-3

\section{NOMENCLATURE}

\section{Latin symbols}

$D T_{\mathrm{SP}} \quad$ deviation of time-averaged temperature at RP in relation to the temperature set, ${ }^{\circ} \mathrm{C}$

measurement point

temperature measuring sensor

number of repeated temperature measurement

expansion factor

mass of a product in a batch, $g$

number of measurements

total number of temperature measuring sensors

experimental standard deviation, ${ }^{\circ} \mathrm{C}$

component of standard error of repeatability, ${ }^{\circ} \mathrm{C}$

duration of TP, min
$T_{\mathrm{GC}} \quad$ temperature in the geometric centre of product after shower cooling, ${ }^{\circ} \mathrm{C}$

$T_{i, d} \quad$ time-averaged temperatures on such measurement points $i,{ }^{\circ} \mathrm{C}$

$T_{i, j} \quad$ set of measured temperatures at measurement points, ${ }^{\circ} \mathrm{C}$

$T_{m j} \quad$ mean temperature value of each measuring sensor, ${ }^{\circ} \mathrm{C}$

$T_{\mathrm{RP}} \quad$ temperature value at $\mathrm{RP},{ }^{\circ} \mathrm{C}$

$T_{\mathrm{RP}, d} \quad$ deviations of time-averaged temperature at $\mathrm{RP},{ }^{\circ} \mathrm{C}$

$T_{\mathrm{SP}} \quad$ temperature value at $\mathrm{SP},{ }^{\circ} \mathrm{C}$

$T_{\mathrm{TP}} \quad$ temperature of $\mathrm{TP},{ }^{\circ} \mathrm{C}$

$u \quad$ standard measurement uncertainty, ${ }^{\circ} \mathrm{C}$

$u_{A} \quad$ uncertainty components determined by statistical methods, ${ }^{\circ} \mathrm{C}$

$u_{B} \quad$ uncertainty components estimated on other ways, ${ }^{\circ} \mathrm{C}$

$u_{c} \quad$ maximum component value of compound measurement uncertainty of the chamber's measurement system, ${ }^{\circ} \mathrm{C}$

$u_{c j} \quad$ component of compound measurement uncertainty of chamber's, measurement system, ${ }^{\circ} \mathrm{C}$

$u_{m j} \quad$ initial value of compound measurement uncertainty, ${ }^{\circ} \mathrm{C}$

$U \quad$ expanded measurement uncertainty, ${ }^{\circ} \mathrm{C}$

$U_{m j} \quad$ estimation value of expanded measurement uncertainty, ${ }^{\circ} \mathrm{C}$

$x_{i, d} \quad$ mean temperature value, ${ }^{\circ} \mathrm{C}$

$x_{\text {air }} \quad$ mean value of all the temperature measurements, ${ }^{\circ} \mathrm{C}$

\section{Greek symbols}

$\delta T_{d} \quad$ maximum temperature instabilities, ${ }^{\circ} \mathrm{C}$

$\Delta T_{C, d} \quad$ maximum spatial temperature gradient through the working space, ${ }^{\circ} \mathrm{C}$

$\Delta T_{\mathrm{RP}, d}$ maximum spatial temperature deviation in relation to the test chamber's RP, ${ }^{\circ} \mathrm{C}$

$\Delta T_{\mathrm{RP}+, d}$ maximum spatial positive deviation of time-averaged temperatures, ${ }^{\circ} \mathrm{C}$

$\Delta T_{\mathrm{RP}-, d} \quad$ maximum spatial negative deviation of time-averaged temperatures, ${ }^{\circ} \mathrm{C}$

$\Delta T_{\mathrm{RP}} / \Delta \tau$ average share of temperature increase at $\mathrm{RP},{ }^{\circ} \mathrm{C} / \mathrm{h}$

\section{Abbreviations}

A $m$, mass of a product in a batch, $\mathrm{g}$

ANOVA analysis of variance

B $\quad T_{\mathrm{TP}}$, temperature of $\mathrm{TP},{ }^{\circ} \mathrm{C}$

C $\quad T_{\mathrm{GC}}$, temperature in the geometric centre of product after shower cooling, ${ }^{\circ} \mathrm{C}$

DOE Design of Experiments

RP reference point

RSM Response Surface Method

SP set point

TP thermal processing of semi-durable meat products

Contact information

Dennis JANKOVICH, MSc

Agencija za opremu pod tlakom

Ulica grada Vukovara 237, 10000 Zagreb, Croatia

E-mail: dennis.jankovich@gmail.com

Krešimir OSMAN, PhD

Termo Servis Ltd.

Miramarska 34, 10000 Zagreb, Croatia

E-mail: kresimir.osman@gmail.com

Vili MILKOVIĆ, MSc

Agencija za sigurnost željezničkog prometa

Radnička cesta 39, 10000 Zagreb, Croatia

E-mail: vilim351@gmail.com 